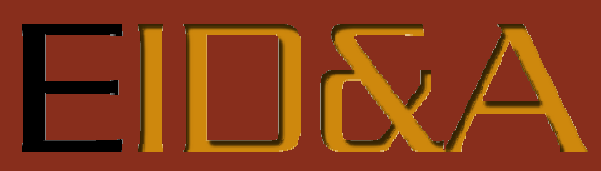

Revista Eletrônica de Estudos Integrados em Discurso e Argumentação

\title{
ARGUMENTAÇÃO EM “ÓBITO DO AUTOR”: PRIMEIRA PARTE DO LIVRO MEMÓRIAS PÓSTUMAS DE BRÁS CUBAS
}

\author{
Fernanda Taís Brignol Guimarães ${ }^{i}$ \\ Neiva M. Tebaldi Gomes ii
}

Resumo: Analisam-se, neste artigo, enunciados da primeira parte do livro Memórias Póstumas de Brás Cubas, "Óbito do Autor", a fim de refletir sobre os sentidos que emergem das memórias do locutor. Para tanto, tomamos como base orientações da Teoria da Argumentação na língua, de Oswald Ducrot e Marion Carel, mais precisamente, valemo-nos do conceito de encadeamentos: normativos, em PORTANTO, e transgressivos, em NO ENTANTO. A análise revela que os sentidos produzidos no texto são acionados por meio dos termos "vida" e "morte", cuja argumentação interna contribui para a construção dos argumentos do locutor, que, na maioria das vezes, apontam para a transgressão, frustrando a expectativa do leitor.

Palavras-chave: Teoria da Argumentação. Sentidos. Argumentação interna. Encadeamentos normativos e transgressivos.

Abstract: In this paper, we analyze statements extracted from the first part of the book Posthumous Memoirs of Brás Cubas, which is named as "Death of the Author". Our focus is to reflect about the meanings that emerge from the speaker's memories. Our theoretical background is anchored in Oswald Ducrot and Marion Carel's Theory of Argumentation Within Language, more precisely, in the concept of chaining: normative, in THEREFORE; and transgressive, in HOWEVER. The analysis reveals that the meanings produced in the text are activated by the terms "life" and "death", whose internal argumentation contributes to the construction of the speaker's arguments, which, in most cases, point to transgression, frustrating the expectation of the reader.

Keywords: Theory of Argumentation. Meanings. Internal argumentation. Normative and transgressive chaining.

\footnotetext{
' Doutoranda em Letras pelo Programa de Pós-Graduação da Associação Ampla UCS/UniRitter. Bolsista CAPES. E-mail: fernandabage@hotmail.com.

ii Doutora em Letras pela Universidade Federal do Rio Grande do Sul (UFRGS), Brasil. E-mail: neivatebaldi@bol.com.br.
} 
EID\&A - Revista Eletrônica de Estudos Integrados em Discurso e Argumentação, llhéus, n. 15, jan./jun.2018.

Uma breve apresentação teórica

Todas essas coisas existem na língua, mas a título de entidades abstratas; [...]. O essencial, porém, é que as entidades abstratas repousam sempre, em última análise, em entidades concretas. (Saussure)

A Teoria da Argumentação na Língua, proposta inicialmente por Oswald Ducrot e Jean-Claude Anscombre, e, mais recentemente, em desenvolvimento com a participação de Marion Carel, parte do pressuposto de que a função mais importante da língua é argumentar. Nessa perspectiva, o sentido é entendido como essencialmente argumentativo e está inscrito na língua por meio de nomes, conjunções, advérbios e outras classes de palavras. Trata-se de uma teoria de base estruturalista, fundamentada em estudos do signo linguístico de Ferdinand de Saussure, no que diz respeito, mais especificamente, às noções de valor e relação.

Para Saussure (2012, p. 163), “o valor de qualquer termo que seja está determinado por aquilo que o rodeia; nem sequer da palavra que significa 'sol' se pode fixar imediatamente o valor sem levar em conta o que lhe existe em redor [...]". Assim, o conceito de valor, que é definido pela relação que um termo mantém com outro no uso da língua, corresponde ao de sentido. A Teoria da Argumentação na Língua trata do valor argumentativo de um termo ou expressão que é entendido como o conjunto de possiblidades e impossibilidades de continuação discursiva. Ou seja, como será explicitado mais adiante, por essa teoria, o valor argumentativo resulta da orientação que a própria palavra dá ao discurso.

Como teoria de base estruturalista, a Teoria da Argumentação na Língua procura constatar de que forma os recursos linguísticos, no nível sintagmático, entendido este como o da ordem e da articulação dos termos nos sintagmas, e no paradigmático, entendido como o das possibilidades de substituição de um termo por outro no sintagma, são significativos para o dizer do Locutor ${ }^{1}$ no processo de enunciação. Por essa perspectiva teórica, o sentido resulta das relações que se estabelecem entre termos nos dois níveis: pelas relações sintagmáticas entre termos do discurso (in praesentia) e, pelas paradigmáticas, entre relações que se produzem fora do discurso (in absentia)

${ }^{1}$ O Locutor, na Teoria da Argumentação na Língua, é o responsável pelo ponto de vista assumido. É um ser discursivo, não empírico. 
EID\&A - Revista Eletrônica de Estudos Integrados em Discurso e Argumentação, llhéus, n. 15, jan./jun.2018.

por associações entre signos que nossa memória estabelece. Segundo Saussure (2012, p. 171), essas relações "correspondem a duas formas de nossa atividade mental, ambas indispensáveis para a vida da língua".

A atividade linguística mental consiste, então, em relacionar formas abstratas da língua para produzir sentidos em contextos reais de comunicação. É assim, por exemplo, que em um enunciado como A casa azul será vendida, o sentido de casa resulta da relação que esse signo mantém com os demais do sintagma. Ou seja, não é qualquer casa que será vendida, tratase de uma casa específica, a casa azul. E ela não será comprada, doada, emprestada e sim vendida. Não faria sentido nessa construção dizer A casa azul é amarela, visto que já há um termo que especifica a cor da casa, azul. No entanto, fazendo outra combinação, seria possível obter, por exemplo, A casa azul e amarela será vendida. Nessa nova associação de termos o sentido de casa já seria outro. Do mesmo modo, não faria sentido inverter a ordem dos termos, dizendo algo como azul a será vendida casa, já que essa é uma construção não prevista pela língua e, portanto, ininteligível para os falantes. Em relação ao eixo paradigmático, que remete a associações (in absentia) e a substituições que podem ser feitas a partir de determinado signo e da posição que ele ocupa na sentença, o termo casa, com valor de substantivo, poderia ser substituído por outro substantivo, como carro, por exemplo, formando nova sentença, como $O$ carro azul será vendido.

Em sua teoria, Ducrot opta pelas relações sintagmáticas e estuda as possibilidades de combinação de um signo com outros signos, observando, por exemplo, o que pode preceder ou seguir esse signo na linearidade do discurso. O objeto de estudo são os encadeamentos argumentativos, entendidos como continuações que certas expressões possibilitam.

No seu desenvolvimento, a Teoria da Argumentação na Língua leva em consideração a atividade de linguagem em si mesma, não o exterior linguístico, ou seja, a realidade, o mundo de que fala a linguagem. Por essa perspectiva, a língua não descreve o mundo, ela o recria em cada situação de uso. Assim concebida, a linguagem mostra a realidade do ponto de vista do locutor (aspecto subjetivo) para fazer desse ponto de vista um tema de debate entre locutor e interlocutor (aspecto intersubjetivo). Dessa forma, a teoria explica que, ao interagir com seu interlocutor, exprimindo sua visão de mundo, o locutor argumenta. 
EID\&A - Revista Eletrônica de Estudos Integrados em Discurso e Argumentação, Ilhéus, n. 15, jan./jun.2018.

É uma teoria que se sustenta no princípio de que a argumentação está na própria língua. Para exemplificá-la, os autores mostram que em um enunciado como $O$ hotel está próximo, portanto é fácil chegar, é a palavra próximo que permite a conclusão portanto é fácil chegar, ou seja, próximo contém o sentido de fácil acesso. A impossibilidade de um encadeamento como $O$ hotel está próximo, portanto é difícil chegar é invocada para demonstrar esse princípio. A ideia central da teoria é a de que o sentido de uma expressão está dado pelos discursos argumentativos que podem encadear-se a partir dessa expressão. Ou seja, é a combinação de hotel e próximo que permite ao operador portanto articular a conclusão é fácil chegar. Segundo Carel e Ducrot (2005, p. 13), a argumentação não se agrega ao sentido, mas constitui o sentido, que resulta dos encadeamentos argumentativos que uma entidade linguística evoca em uma determinada combinação, ou seja, em um determinado uso da linguagem.

Admitir que o sentido se define no uso é considerar a ação humana realizada pela linguagem, o que leva a uma articulação entre semântica e pragmática, porque, segundo os autores (ANSCOMBRE; DUCROT, 1994, p. 9, nota 4), "não se pode pensar que exista na significação um setor puramente objetivo que não esteja contaminado de intenções pragmáticas". Trata-se, no entanto, segundo Ducrot (1987, p. 163), não mais de saber o que se faz quando se fala (tarefa da pragmática), mas do que se considera que a fala faz pelo enunciado. A questão é saber por que certas palavras, em certas circunstâncias, são mais eficazes para exercer influência sobre o interlocutor.

Subjacente a essa semântica pragmática está o conceito de teoria polifônica da enunciação $0^{2}$ que permite relacionar as sequências articuladas pelos operadores argumentativos a posições ou perspectivas (pontos de vista) recuperáveis no interior dos enunciados. Segundo essa perspectiva, um enunciado pode apresentar nele vários sujeitos com diferentes funções: o sujeito empírico (que não é objeto de estudo do linguista), o locutor (que é responsável pelo enunciado) e os enunciadores (origens de pontos de vista, pontos de perspectivas, não pessoas). Os enunciadores não têm palavras, mas suas "vozes" estão implícitas nos enunciados. É frente a esses enunciadores

\footnotetext{
${ }^{2}$ Ducrot, 1988, p. 163 , afirma que a sua teoria polifônica deve muito à teoria de Bakhtin sobre literatura, mas é preciso salientar que na sua teoria o termo assume um outro sentido. Bakhtin tomou emprestado da música o termo polifonia (que designa um tipo de composição em que diferentes partituras, diferentes vozes se superpõem) para designar dois tipos de discursos literários: um dogmático, monológico e, outro, em que os personagens se apresentam por seus discursos, sem que um se sobressaia aos demais.
} 
EID\&A - Revista Eletrônica de Estudos Integrados em Discurso e Argumentação, llhéus, n. 15, jan./jun.2018.

que o locutor se posiciona, toma atitudes de concordância, de identificação, de rejeição e expõe pontos de vista sobre os temas, constituindo, desse modo, a sua própria argumentação. Para exemplificar essa polifonia, consideremos um enunciado como $O$ deputado $X$ não é corrupto. Aqui há um locutor que se posiciona frente a dois pontos de vista: $O$ deputado $X$ é corrupto e $O$ deputado $X$ não é corrupto.

Por essa perspectiva teórica, a linguagem não dá acesso direto à realidade. Quando a linguagem descreve a realidade o faz pelos aspectos subjetivo e intersubjetivo, tornando-se essa realidade tema de debate entre indivíduos. O caráter subjetivo evidencia-se na expressão do locutor e o intersubjetivo na ação do locutor sobre o interlocutor. Nas palavras do autor,

Não acredito que a linguagem ordinária possua uma parte objetiva muito menos que os enunciados da linguagem dêem acesso à realidade; em todo caso, não a descrevem diretamente. Em minha opinião, se a linguagem ordinária a descreve, ela o faz através dos aspectos subjetivos e intersubjetivos (DUCROT, 1988, p. 50, tradução nossa). ${ }^{3}$

Para explicar sua recusa à possibilidade de a língua descrever a realidade (descrição objetiva), Ducrot explica que ao dizer, por exemplo, Pedro é inteligente, a descrição de Pedro estaria muito ligada à admiração subjetiva que Pedro desperta no locutor. Com isso quer dizer que a palavra inteligência não significa nada se não for levada em consideração essa admiração. Nesse sentido, falar é tratar de impor aos outros um modo particular de apreensão da realidade. E é desse modo que o locutor se marca no enunciado, deixando nele "pistas" que orientam uma determinada interpretação.

É assim também que, em um enunciado, os operadores argumentativos (conjunções, advérbios e uma gama de outras expressões que nem sempre encontram uma classificação específica nas categorias relacionadas pelas gramáticas tradicionais) tornam-se "pistas" importantes deixadas pelo locutor. Tais operadores assumem dupla função: organizam as partes que compõem um enunciado, explicitando as relações de sentido que decorrem dessa forma de organização e conduzem o leitor a determinada conclusão.

\footnotetext{
${ }^{3}$ No original: "No creo que el linguaje ordinário posea una parte objetiva ni tampoco creo que los enunciados del linguaje den acceso a la realidade; em todo caso no la describren diretamente. A mi modo de ver, si el linguaje ordinário la describe, lo hace por intermédio de los aspectos subjetivo e intersubjetivo" (DUCROT, 1988, p. 50).
} 
EID\&A - Revista Eletrônica de Estudos Integrados em Discurso e Argumentação, llhéus, n. 15, jan./jun.2018.

Dentre os conceitos utilizados para explicar a Teoria da Argumentação na Língua, além do conceito de relação, destacam-se o de significação e sentido, frase e enunciado. A significação corresponde ao valor semântico da frase; em outras palavras, a significação está na língua como possibilidade. $O$ sentido é o valor semântico do enunciado, ou seja, resulta de um ato de enunciação. Como resultado de um ato de enunciação, o sentido é sempre único. Frase e enunciado correspondem respectivamente aos conceitos de língua e fala de Saussure. Assim, a frase designa uma estrutura abstrata, uma entidade teórica; o enunciado, uma realidade empírica constituída de dois segmentos, como em Pedro é inteligente (S1); será aprovado no concurso (S2).

No enunciado acima, é a palavra inteligente ( $\mathrm{S} 1$ ) que permite o encadeamento será aprovado no concurso (S2), subentendendo-se na conexão dos dois segmentos um PORTANTO. Por resultar da orientação dada pela língua, tem-se um encadeamento dito normativo, ou encadeamento em PORTANTO. Transgredindo essa orientação já prevista na língua, seria possível dizer Pedro é inteligente, no entanto não será aprovado. Ter-se-ia, assim, um encadeamento em NO ENTANTO, dito transgressivo. PORTANTO e NO ENTANTO são protótipos, ou abstrações, de duas formas de encadear ideias. Em situações concretas de uso da língua, esses conectores podem concretizarse com inúmeros outros termos, podendo ficar, inclusive apenas subentendidos. Reflexões dessa natureza revelam que a argumentação está realmente prevista na língua, na medida em que as palavras possuem já uma argumentação interna que, na produção de enunciados, se revela nas possibilidades ou impossibilidades de continuação. É nesse sentido que Carel (2009, p. 26) afirma que "[...] falar consiste, não em nomear, mas em relacionar as palavras em frases, em parágrafos, em textos, de modo que a descrição de uma palavra permita a descrição dos enunciados em que está empregada". Em Pedro é inteligente; será aprovado no concurso, é a descrição de inteligente que permite a descrição do sentido do enunciado.

Tomando por suporte teórico noções da Teoria da Argumentação, este artigo analisa enunciados da primeira parte do livro Memórias Póstumas de Brás Cubas: "Óbito do Autor", focalizando as relações de sentido produzidas a partir do emprego das palavras vida e morte, bem como das palavras dela derivadas ou pertencentes ao mesmo campo semântico. A análise parte da argumentação construída por meio dos encadeamentos normativos (em 
EID\&A - Revista Eletrônica de Estudos Integrados em Discurso e Argumentação, Ilhéus, n. 15, jan./jun.2018.

PORTANTO) e transgressivos (em NO ENTANTO), a fim de chegar à descrição de possíveis sentidos do texto.

Uma análise da argumentação interna de enunciados presentes em “Óbito do Autor"

“Óbito do Autor" (texto transcrito abaixo) constitui a primeira parte do livro Memórias Póstumas de Brás Cubas, de Machado de Assis. No texto, transgredindo a forma canônica, a narrativa é construída da perspectiva de um defunto, a personagem Brás Cubas, que narra suas memórias póstumas, partindo do relato da sua própria morte e da descrição do ritual que constituiu seu enterro. Uma primeira leitura do texto revela uma construção sustentada na ideia de morte, que é constantemente reafirmada por termos de mesma carga semântica, negritados na transcrição para fins de análise. A morte opõese à vida, referida, no início do texto, pelos termos princípio e nascimento, empregados para mostrar hesitação e discordância em relação ao uso vulgar, no dizer do locutor, de abrir memórias. A palavra vida volta no final do texto, na descrição do processo da morte, em a vida estrebuchava-me no peito.

Para fins de análise, o texto foi transcrito abaixo com palavras em destaque: negritos e itálicos. A descrição da organização argumentativa encadeamentos normativos e encadeamentos transgressivos - efetiva-se pela transcrição de excertos.

1 - Óbito do Autor

Algum tempo hesitei se devia abrir estas memórias pelo princípio ou pelo fim, isto é, se poria em primeiro lugar o meu nascimento ou a minha morte. Suposto o uso vulgar seja começar pelo nascimento, duas considerações me levaram a adotar diferente método: a primeira é que eu não sou propriamente um autor defunto, mas um defunto autor, para quem a campa foi outro berço; a segunda é que o escrito ficaria assim mais galante e mais novo. Moisés, que também contou a sua morte, não a pôs no intróito, mas no cabo: diferença radical entre este livro e o Pentateuco.

Dito isto, expirei às duas horas da tarde de uma sexta-feira do mês de agosto de 1869, na minha bela chácara de Catumbi. Tinha uns sessenta e quatro anos, rijos e prósperos, era solteiro, possuía cerca de trezentos contos e fui acompanhado ao cemitério por onze amigos. Onze amigos! Verdade é que não houve cartas nem anúncios. Acresce que chovia - peneirava - uma chuvinha miúda, triste e constante, tão constante e tão triste, que levou um daqueles fieis da última hora a intercalar esta engenhosa idéia no discurso que proferiu à beira da minha cova: - "vós, que o conhecestes, meus senhores, vós que podeis dizer comigo que a natureza parece estar chorando a perda irreparável de um dos mais belos caracteres que tem honrado a humanidade. Este ar sombrio, estas gotas do céu, aquelas nuvens escuras que cobrem o azul como um crepe funéreo, tudo isso é 
EID\&A - Revista Eletrônica de Estudos Integrados em Discurso e Argumentação, llhéus, n. 15, jan./jun.2018.

a dor crua e má que lhe rói à natureza as mais íntimas entranhas. Tudo isso é um sublime louvor ao nosso ilustre finado."

Bom e fiel amigo! Não, não me arrependo das vinte apólices que the deixei. E foi assim que cheguei à cláusula dos meus dias; foi assim que me encaminhei para $o$ undiscovered country de Hamlet, sem as ânsias nem as dúvidas do moço príncipe, mas pausado e trôpego, como quem se retira do espetáculo. Tarde e aborrecido. Viram-me ir umas nove ou dez pessoas, entre elas três senhoras, minha irmã Sabina, casada com Cotrim, - a filha, um lírio-do-vale, - e... Tenham paciência! daqui a pouco lhes direi quem era a terceira senhora. Contentem-se de saber que essa anônima, ainda que não parenta, padeceu mais do que as parentas. É verdade, padeceu mais. Não digo que se carpisse, não digo que se deixasse rolar pelo chão, convulsa. Nem o meu óbito era coisa altamente dramática... Um solteirão que expira aos sessenta e quatro anos, não parece que reúna em si todos os elementos de uma tragédia. E dado que sim, o que menos convinha a essa anônima era representá-lo. De pé, à cabeceira da cama, com os olhos estúpidos, a boca entreaberta, a triste senhora mal podia crer na minha extinção.

- Morto! morto! dizia consigo.

É a imaginação dela, como as cegonhas que um ilustre viajante viu desferirem o vôo desde o llisso às ribas africanas, sem embargo das ruínas e dos tempos, - a imaginação dessa senhora também voou por sobre os destroços presentes até às ribas de uma África juvenil... Deixá-la ir; lá iremos mais tarde; lá iremos quando eu me restituir aos primeiros anos. Agora, quero morrer tranqüilamente, metodicamente, ouvindo os soluços das damas, as falas baixas dos homens, a chuva que tamborila nas folhas de tinhorão da chácara, e o som estrídulo de uma navalha que um amolador está afiando lá fora, à porta de um correeiro. Juro-lhe que essa orquestra da morte foi muito menos triste do que podia parecer. De certo ponto em diante chegou a ser deliciosa. A vida estrebuchava-me no peito, com uns ímpetos de vaga marinha, esvaía-se-me a consciência, eu descia à imobilidade física e moral, e o corpo fazia-se-me planta, e pedra, e lodo, e coisa nenhuma.

Morri de uma pneumonia; mas se lhe disser que foi menos a pneumonia, do que uma idéia grandiosa e útil, a causa da minha morte, é possível que o leitor me não creia, e todavia é verdade. Vou expor-Ihe sumariamente o caso. Julgue-o por si mesmo.

Pelos termos em destaque (negritos e itálicos), constata-se que os sentidos do texto são acionados a partir dos termos vida e morte, período que compreende o tempo da narrativa, que começa pelas memórias da morte e não pelas do nascimento, uso vulgar, do ponto de vista do locutor. Essa primeira transgressão poderia ser parafraseada da seguinte forma: Defunto NO ENTANTO narrador.

Como justificativa para sua decisão de optar por iniciar a narrativa pelo fim (significando morte e, ao mesmo tempo, fim da narrativa), o locutor aponta duas razões: a primeira é a de não ser ele um autor defunto, mas um defunto autor, jogo de palavras que justificam a construção de suas memórias 
EID\&A - Revista Eletrônica de Estudos Integrados em Discurso e Argumentação, Ilhéus, n. 15, jan./jun.2018.

pelo fim e que, ao mesmo tempo, o definem; a segunda diz respeito ao estilo da narrativa, o escrito ficaria assim mais galante e mais novo.

Seguem, abaixo, o primeiro excerto e as paráfrases que a ele podem ser associadas.

Excerto 1:

Algum tempo hesitei se devia abrir estas memórias pelo princípio ou pelo fim, isto é, se poria em primeiro lugar o meu nascimento ou a minha morte. Suposto o uso vulgar seja começar pelo nascimento, duas considerações me levaram a adotar diferente método: a primeira é que eu não sou propriamente um autor defunto, mas um defunto autor, para quem a campa foi outro berço; a segunda é que o escrito ficaria assim mais galante e mais novo. Moisés, que também contou a sua morte, não a pôs no intróito, mas no cabo: diferença radical entre este livro e o Pentateuco.

Possíveis paráfrases para o excerto 1:

Memórias NO ENTANTO começar pelo fim e não pelo nascimento Não começar pelo nascimento PORTANTO não uso vulgar

Ser defunto autor PORTANTO diferente método

Note-se que a argumentação gira em torno da palavra morte, retomada, no excerto acima, por termos de mesma carga semântica: fim e defunto. A argumentação interna do termo defunto, em defunto autor, é o que assegura a construção transgressiva da narrativa de iniciar pela morte do narrador e não pelo seu nascimento. O fato de ser um defunto autor tira-lhe a responsabilidade de seguir cânones de escrita e, dessa forma, Ihe dá o direito de inverter a ordem comumente usada e de inovar (transgredir).

A palavra morte e os termos e expressões equivalente utilizados no texto, fim, extinção, óbito, última hora, finado, defunto e outras, em encadeamentos normativos remeteriam a melancolia, tristeza, dor, choro, desespero. Mas, novamente, acontece a transgressão do que é esperado pelo leitor, pois o locutor descreve sua morte como uma não tragédia, conforme pode ser constatado no excerto 2:

Nem o meu óbito era coisa altamente dramática... Um solteirão que expira aos sessenta e quatro anos, não parece que reúna em si todos os elementos de uma tragédia.

... que pode ser parafraseado da seguinte forma:

Morte PORTANTO tristeza, tragédia, perda, dor

Morte de um solteirão de sessenta e quatro anos NO ENTANTO não tragédia. 
EID\&A - Revista Eletrônica de Estudos Integrados em Discurso e Argumentação, Ilhéus, n. 15, jan./jun.2018.

Tem-se, nesse caso, um enunciado transgressivo em NO ENTANTO: Morte, no entanto, não tragédia, em que a força argumentativa está no termo solteirão, que remete a alguém solitário, provavelmente sem filhos. Sendo a morte uma tragédia para os familiares, a morte de um solteirão (alguém que não constituiu sua própria família) pode consistir em uma não tragédia. $A$ idade 64 anos reforça a argumentação de não se tratar de uma tragédia visto que já teria vivido um tempo considerável. Em relação à morte de um jovem, sim, seria comum se ouvir: “Que tragédia!”, “Uma pessoa tão jovem, ainda nem viveu o bastante!”, "Não teve tempo de aproveitar a vida." A palavra solteirão, que por sua terminação remete a homem "não jovem", reforça a ideia de morte no entanto não tragédia, encadeamento transgressivo que sustenta a descrição dos ritos do enterro.

A ideia morte no entanto não tragédia repete-se na descrição da orquestra da morte: menos triste... deliciosa.

Excerto 3:

Juro-lhe que essa orquestra da morte foi muito menos triste do que podia parecer. De certo ponto em diante chegou a ser deliciosa. A vida estrebuchavame no peito, com uns ímpetos de vaga marinha, esvaía-se-me a consciência, eu descia à imobilidade física e moral, e o corpo fazia-se-me planta, e pedra, e lodo, e coisa nenhuma.

A primeira parte do excerto poderia ser parafraseada da seguinte forma:

Orquestra da morte, NO ENTANTO não triste

A segunda parte descreve o processo da morte como transformação: corpo fazia-se-me planta..., cuja paráfrase poderia ser:

Morte PORTANTO transformação.

A significação da palavra orquestra aponta para uma coletividade de sons, um conjunto de sons, conjunto musical. Portanto Orquestra da morte pode indicar aqui o conjunto, o todo que envolve a morte, o ritual da morte: velório, enterro, choro, despedida, tristeza, melancolia etc. No texto, a transgressão da orientação fornecida pela expressão orquestra da morte quebra a expectativa do leitor, fornecendo-lhe outra orientação: De certo ponto em diante chegou a ser deliciosa. A força argumentativa do adjetivo deliciosa reforça a possibilidade de quebra de expectativa, já que põe a experiência da morte num patamar de um sentido tátil. 
EID\&A - Revista Eletrônica de Estudos Integrados em Discurso e Argumentação, Ilhéus, n. 15, jan./jun.2018.

Ainda sobre esse excerto, a sequência e o corpo fazia-se-me planta, $e$ pedra, e lodo, e coisa nenhuma parece representar o ritmo da orquestra da morte. Da leitura desses termos assim como foram encadeados parece emergir um som de marcha, que remete à marcha fúnebre. Esse encadeamento das palavras, numa sequência que faz emergir um ritmo, reforça o sentido da palavra orquestra, ligado a som, música, melodia, ritmo e se traduz no sentido do enunciado: morte não tristeza, transformação. Mas na sequência e o corpo fazia-se-me planta, e pedra, e lodo, e coisa nenhuma revelase também um processo crescente de degeneração do corpo: de planta, que ainda lembra vida, a coisa nenhuma.

No excerto 4 , tem-se o relato de detalhes temporais e espaciais da morte do locutor, bem como uma autodescrição, seguida de detalhes do próprio funeral:

[...] expirei às duas horas da tarde de uma sexta-feira do mês de agosto de 1869, na minha bela chácara de Catumbi. Tinha uns sessenta e quatro anos, rijos e prósperos, era solteiro, possuía cerca de trezentos contos e fui acompanhado ao cemitério por onze amigos. Onze amigos! Verdade é que não houve cartas nem anúncios. Acresce que chovia - peneirava - uma chuvinha miúda, triste e constante.

É comum esperar que os enterros reúnam muitas pessoas, ou, pelo menos, um número considerável de pessoas. Porém, no caso de Brás Cubas compareceram apenas onze amigos. Fato este que é ressaltado no texto por meio da repetição da palavra onze e do ponto de exclamação que a segue. Nas paráfrases abaixo, é possível perceber como o locutor argumenta em seu favor ao apontar para a ausência de cartas ou anúncios e ainda acrescentando o fato de estar chovendo:

Haver cartas e anúncios, PORTANTO, possibilidade de comparecer mais pessoas Não haver cartas nem anúncios, PORTANTO, possibilidade de poucas pessoas Estar chovendo, portanto, menos pessoas comparecerem

A argumentação interna da palavra anúncio (algo anunciado, avisado) orienta para a possibilidade de comparecimento de mais pessoas em eventos ou acontecimentos: aniversários, casamentos, velórios... Na narrativa, o enunciado negativo não houve cartas nem anúncios justifica o comparecimento de apenas onze amigos, fato reforçado pelo acréscimo da chuva.

Por fim, o locutor compara sua morte com a morte de Hamlet, porém com ressalvas em relação a do moço príncipe, conforme mostra o excerto 5 : 
EID\&A - Revista Eletrônica de Estudos Integrados em Discurso e Argumentação, llhéus, n. 15, jan./jun.2018.

E foi assim que cheguei à cláusula dos meus dias; foi assim que me encaminhei para o undiscovered country de Hamlet, sem as ânsias nem as dúvidas do moço príncipe, mas pausado e trôpego, como quem se retira do espetáculo. Tarde e aborrecido.

A comparação da morte, em como quem se retira do espetáculo. Tarde e aborrecido, demonstra descontentamento em relação ao fim da vida (cláusula dos meus dias) e a uma morte comum, sem grandiosidade e eloquência. Essa morte explica os encadeamentos transgressivos constitutivos da argumentação no texto: a morte como não tragédia, que reúne poucos amigos. Essa transgressão de sentido da palavra morte, portanto, é o que sustenta toda a argumentação do locutor, que ora se conforma com seu final não glorioso, ora tenta ludibriar a si mesmo, como no caso das justificativas dadas para o fato de terem comparecido apenas onze amigos em seu enterro.

\section{Considerações finais}

Pela perspectiva da Teoria da Argumentação da Língua, as palavras já possuem uma orientação argumentativa (argumentação interna), que aponta para possibilidades de encadeamentos ditos normativos (em PORTANTO, que confirmam a orientação dada), mas que com exploração de recursos da língua essa orientação também deixa a possibilidade de encadeamentos transgressivos (em NO ENTANTO, que atribuem à palavra outra orientação, subvertendo a lógica esperada pelo interlocutor de um enunciado).

Com a análise ainda que um tanto embrionária da primeira parte do livro de Machado de Assis, Memórias Póstumas de Brás Cubas, "Óbito do Autor”, foi possível constatar que conceitos da Teoria da Argumentação podem contribuir para a explicitação dos sentidos de um texto. Os enunciados descritos revelam "Óbito do Autor" como uma narrativa embasada fundamentalmente em encadeamentos transgressivos. São encadeamentos relacionados a um universo de sentido compreendido entre vida e morte do locutor. Também foi possível constatar que as palavras vida e morte (ideias reafirmadas em termos e expressões equivalentes) assumiram, na narrativa, sentidos não previstos na língua graças às relações que se estabeleceram entre as palavras que constituíram sintagmas e enunciados.

Por fim, a decisão de começar uma narrativa memorialística pela morte e não pelo nascimento constitui, certamente, a primeira transgressão do locutor que, a partir daí, adentra em um verdadeiro jogo semântico, explorando 
EID\&A - Revista Eletrônica de Estudos Integrados em Discurso e Argumentação, Ilhéus, n. 15, jan./jun.2018.

inúmeras possibilidades de encadeamentos a partir do par opositivo vida e morte. Com uma maior incidência de encadeamentos transgressivos, a narrativa assume um estilo em que predomina a quebra constante de expectativas do interlocutor em relação à ideia de morte e em relação ao fim pouco glorioso do locutor, Brás Cubas.

\section{Referências}

ANSCOMBRE, Jean-Claude; DUCROT, Oswald. La argumentación en la lengua. Madrid: Gredos, 1994.

ASSIS, Machado de. Memórias póstumas de Brás Cubas. São Paulo: FTD, 1998.

CAREL, Marion. Análise argumentativa do léxico: o exemplo da palavra 'medo'. Letras de Hoje. Porto Alegre, v. 44, n. 1, p. 26-33, jan./mar. 2009.

; DUCROT, Oswald. La semántica argumentativa. Una introducción a la Teoria de los Bloques Semánticos. Buenos Aire: Colihue, 2005.

DUCROT, Oswald. Argumentação retórica e argumentação linguística. Letras de Hoje. Porto Alegre, v. 44, n. 1, p. 20-25, jan./mar. 2009. 1987.

. O Dizer e o Dito. Trad. Eduardo Guimarães. Campinas, São Paulo: Pontes,

- Polifonia y Argumentacion. Conferências del Seminário: Teoria de la Argumentacion y Analisis del Discurso. Cali: Universidad del Valle, 1988.

SAUSSURE, Ferdinand de. Curso de linguística geral. Lisboa: Dom Quixote, 1971.

. Curso de Linguística Geral. 28.ed. São Paulo: Cultrix, 2012.

Forma de citação sugerida:

GUIMARÃES, Fernanda Taís Brignol; GOMES, Neiva Tebaldi. Argumentação em "Óbito do autor": primeira parte do livro Memórias Póstumas de Brás Cubas. EID\&A - Revista Eletrônica de Estudos Integrados em Discurso e Argumentação, Ilhéus, n. 15, p. 71-83, jan./jun.2018.

Recebido em: 28/03/2018

Aprovado em: 10/06/2018 